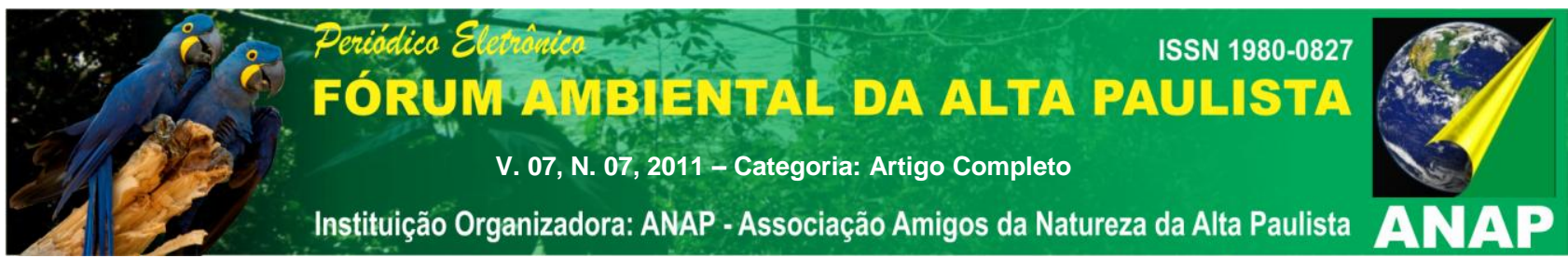

\title{
ARTIGOS/REPORTAGENS E ESSÊNCIA CIENTÍFICA EM SUSTENTABILIDADE
}

\author{
Valter Guimarães ${ }^{1}$ \\ Alcimari Marin de Souza ${ }^{2}$ \\ Vanessa Araujo da Silva Matos ${ }^{3}$
}

\begin{abstract}
RESUMO: A aceitação e credibilidade em tempos modernos exigem que os fatos provenham de fonte segura de investigação, preferencialmente que seus resultados indiquem produção de conhecimento científico. Neste artigo buscou-se trazer para discussão a forma como artigos/reportagens publicados na mídia escrita mostrem se os fatos/resultados ali apresentados/revelados contribuem para o entendimento dos leitores - considerados aqui em algumas das edições da revista Veja nos anos de 2007/2008 - as questões que tratam das problemáticas relacionadas aos avanços das atividades rurais em suas relações com as questões de sustentabilidade ambiental. A veiculação destas informações mostra, de forma direta, por um lado a preocupação com as atividades de desmatamentos, mas por outro revela a importância dos avanços tecnológicos para o desenvolvimento econômico em nosso pais. Os encaminhamentos permitiram procedimentos de leitura e seleção de artigos/reportagens e suas interpretações correlacionadas com algumas obras do campo do conhecimento científico em Geografia, contribuindo para aferir resultados que indicaram maior interesse em divulgação de notícias do que a busca de entendimento em ciência. Para uma possível gama de leitores, principalmente assinantes, concluiu-se pela necessidade de maiores investimentos na busca investigativa o que, de certa forma, poderia estar oferecendo maior segurança e credibilidade nas informações divulgadas.
\end{abstract}

Palavras chaves: Notícia. Investigação. Sustentabilidade.

\footnotetext{
${ }^{1}$ Prof. Associado - UFMS/CPAQ - e-mail; vgeovalter@gmail.com

${ }^{2}$ Acadêmica Geografia UFMS/CPAQ - e-mail: alcimarimarindesouza@hotmail.com

${ }^{3}$ Acadêmica Geografia UFMS/CPAQ - e-mail: nessa ester@hotmail.com
} 


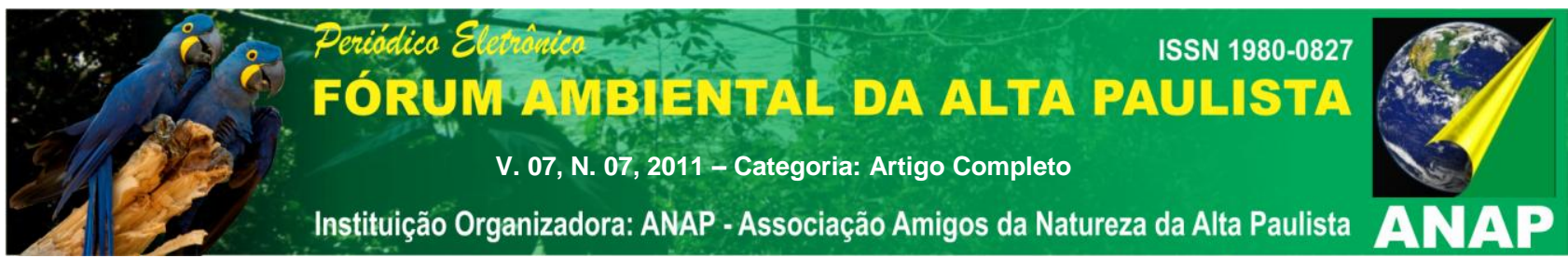

\section{INTRODUÇÃO}

A leitura das publicações editadas em finais do século passado na Revista Veja, cujo foco central foi o de mostrar e trazer à reflexão temas tratando das questões ambientais principalmente aquelas em que há destaques para o embate entre a expansão das fronteiras de uso da terra com a prática da sustentabilidade, foi o que motivou a elaboração deste artigo, que tem como objetivo procurar, dentre elas, aquelas cujo eixo da sustentabilidade ambiental tenha sido o de preocupação mais enfatizada nos assuntos abordados. Esses artigos foram pesquisados nas edições de janeiro a dezembro dos anos de 2007 a 2008, entre eles estão: Revista Veja especial de capa ㄲo 36 - Edição 2008. Equipe Veja: Um dia muito especial; Revista Veja № 29 - Edição 2008. Autores: Daniel Biasetto e Mariana Amaro: Os dilemas da Amazônia; Revista Veja № 40 - Edição 2008. Autor Ronaldo Soares: O Governo desmatador; Revista Veja № 30 - Edição 2008. Autor Diogo Schelp: O lugar mais Preservado do Planeta; Revista Veja № 25 - Edição 2007. Autor: Leonardo Coutinho: Assim não dá; Revista Veja № 23 - Edição 2008. Autora Roberta de Abreu Lima: Muita retórica, pouca ação; Revista Veja № 42 - Edição 2007. Autores Okky de Souza e Vanessa Vieira: SOS terra países e pessoas agem...mas alguns ainda duvidam; Revista Veja No. 12 - Edição 2008. Autores Leonardo Coutinho e José Edward: Especial Amazônia; e, Revista Veja no. 39. Edição 2007. Autores Heloisa Joly e Leonardo Coutinho: O combustível de Lula. Em seguida buscou-se apoio na literatura notadamente geográfica como fundamentação teórica para o entendimento de possíveis bases cientificas nos artigos pesquisados. Dentre as obras consultadas discussões relacionadas à Geografia e Meio Ambiente no Brasil, 1998 de autoria de Antonio Christofoletti; Processos interativos Homem - Meio Ambiente, de D. Drew, 1989. Tradução de J. Santos e Revisão de S. Bastos e Os Domínios da Natureza no Brasil de Aziz Nacib Ab'Saber, 2003.

\section{DESENVOLVIMENTO}




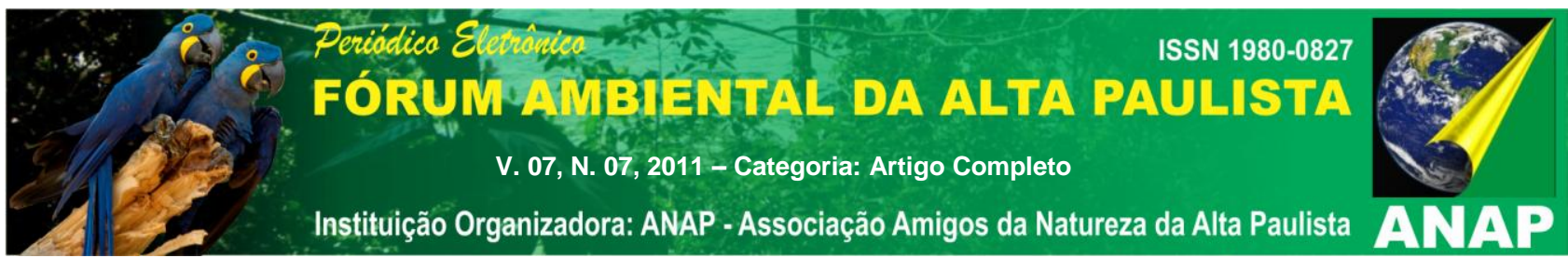

\section{Resumos dos artigos/reportagens selecionados}

Aqui se procurou resumir dando ênfase a partes importantes de cada artigo em cada uma das revistas. Para facilitar o entendimento, destacamos cada um dos artigos selecionados e as respectivas ênfases:

\section{Edição 2008/36: Um dia muito especial.}

Nesta reportagem, na forma de seminário, a revista reuniu personalidades, dentre elas aquelas ligadas diretamente à questão ambiental, de onde se tirou a frase "Tornar mais vantajoso manter uma árvore em pé do que cortá-la". Inicialmente, destacou-se o fato de que cerca de 10 milhões de Habitantes da chamada Amazônia Legal depende das atividades extrativistas ou agropecuárias. Para aquelas pessoas não adianta ficar dando cursos e mais cursos sobre a preservação ambiental e sim dar incentivos que mostrem que é mais vantajoso manter a floresta preservada do que depredá-la.

Um estudo mostra que em Mato Grosso dar mil reais ao ano por hectare preservado serviriam de estímulo suficiente para conter a devastação. Tal publicação não diz como o estudo ocorreu. Portanto, publicar apenas assim seria também incentivo à tal prática?

Edição 2008/29: Os dilemas da Amazônia

Quando, da primeira reportagem de capa em 1970, a Amazônia já era apontada como um dos maiores desafios brasileiros que era o de encontrar formas de conciliar a 


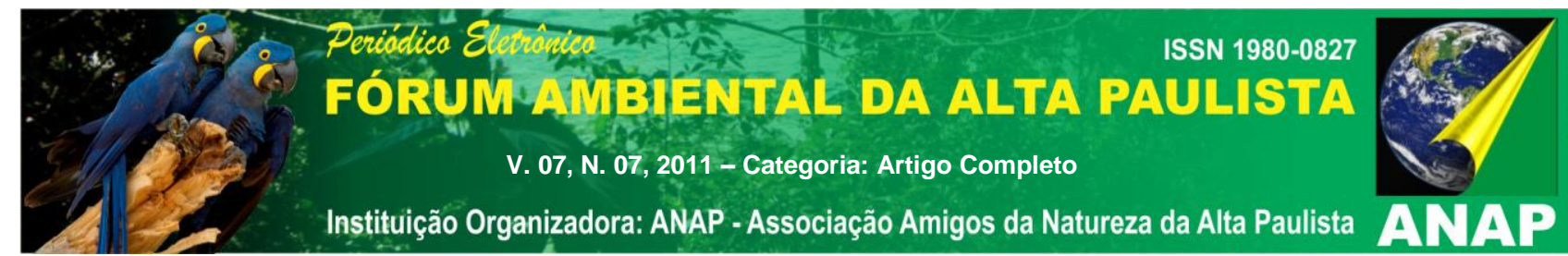

preservação da maior floresta tropical do mundo com o desenvolvimento do potencial econômico dessa região que representa $60 \%$ do território brasileiro.

Segundo os autores deste artigo, ao longo dos seus 40 anos a revista fez dezenas de reportagens. Entre elas algumas são destaques de capas e uma em edição especial, denunciando o efeito desmatador das queimadas e a extração ilegal de madeira, assim como, um avanço desordenado da pecuária e das lavouras de soja nas bordas da Amazônia.

Em março de 2008, a revista chama a atenção para as ações do governo que estava sendo contraditória, pois ao mesmo tempo em que busca reprimir o desmatamento contribui-se decisivamente para ele ao promover assentamentos de Sem-Terras em área de floresta e neste ano o desmatamento da cobertura original da Amazônia atingiu 17\%.

No final deste assunto concluem que atualmente já se tem estudo e recursos suficientes para permitir a ocupação da Amazônia sem alterar seu biossistema. Apenas mencionam a existência de estudo, mas nada foi acrescentado a respeito.

\section{Edição 2008/40: O Governo Desmatador}

Segundo o autor, foi realizado um levantamento dos maiores desmatadores da Amazônia em 2006 e em 2007, e o então ministro do Meio Ambiente Carlos Minc divulgou uma lista dos 100 maiores desmatadores da Amazônia.

No topo desta lista estão seis assentamentos do INCRA responsável pela derrubada de 223.000 hectares de floresta, que equivale a uma área e meia da cidade de São Paulo.

Os assentamentos são responsáveis por $20 \%$ de todo o desmatamento da Amazônia, mostrando que a política fundiária praticada no Brasil é retrógrada e ineficaz. 


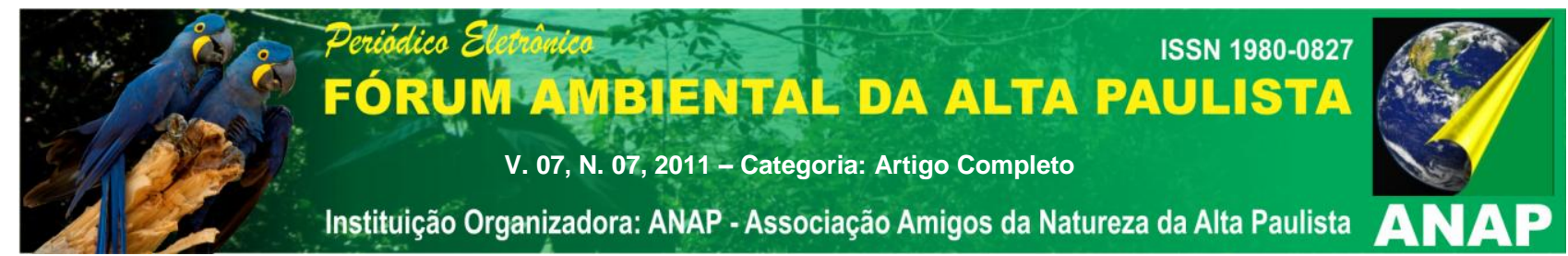

Ainda, o autor deixa claro que este modelo de reforma agrária é um incentivo ao desmatamento, pois as famílias dos Sem-Terras são colocadas no meio da mata sem ter condições de sustentar-se e não recebem assistência técnica adequada que possa orientá-los sobre o uso da terra e o manejo florestal. Também lhes faltam equipamentos e infra estrutura, muitas vezes não conseguindo produzirem para sua própria subsistência tendo que vender ou arrendar seus lotes tornando assim uma fácil presa para os madeireiros.

\section{Edição 2008/14: A Floresta vira Soja}

O artigo enfatiza de acordo com INPE, que o Estado de Mato Grosso abriga 19 dos 36 municípios que mais desmataram áreas de floresta amazônica no último semestre de 2008 e o governador do Estado de Mato Grosso Blairo Maggi que é produtor rural diz que esta informação é mentirosa e que ele iria encomendar novos estudos.

O desmatamento na porção Mato-grossense da Amazônia já extrapolou todos os limites. Nas últimas décadas $129000 \mathrm{~km}^{2}$ da floresta, mais de um terço da devastação total ocorrida no período ocorreu naquela região e cerca de $40 \%$ da cobertura florestal do Estado já foi eliminada, isso corresponde ao dobro do índice global de desmatamento da Amazônia.

A ocupação na porção Amazônica de Mato Grosso é resultado da expansão da fronteira agrícola que a partir da década de 70 transformou as regiões de cerrado no Centro Oeste no principal celeiro produção de alimentos no país, e nos últimos anos extrapolou para o interior da floresta.

Os produtores rurais da região estão fazendo parcerias com ONGs para melhorar as práticas ambientais em suas propriedades e como já desmataram mis de $50 \%$ de suas áreas de florestas eles abriram as porteiras das fazendas para que as ONGs façam um 


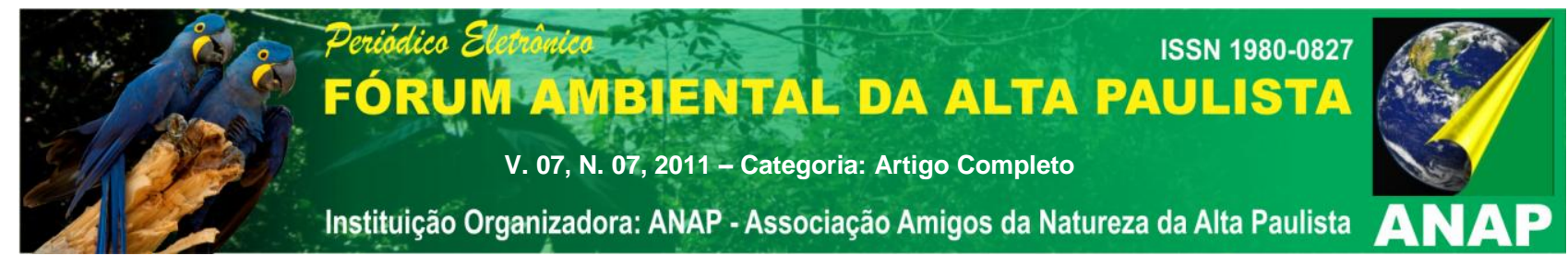

diagnóstico sócio-ambiental da área. Todos assinaram um termo pelo qual se comprometem a recuperar áreas de proteção ambiental e não utilizar trabalho escravo nas fazendas.

\section{Edição 2007/42: SOS terra países e pessoas agem....mas alguns ainda duvidam.}

Conforme os autores desta reportagem, a realidade do aquecimento global criou uma preocupação com o ambiente como nunca se viu. Todo mundo quer fazer sua parte para salvar o planeta. Nesse cenário, vale apenas conhecer a lista de prioridades dos cientistas céticos - aqueles que desconfiam de previsões catastróficas - quando confrontadas àquelas defendidas pelos ambientalistas.

Destacaram-se aqui as contradições entre ambientalistas e céticos:

1ํ $O$ Painel Intergovernamental sobre Mudanças Climáticas (IPCC) afirma que a causa principal do aquecimento é a emissão de dióxido de carbono $\left(\mathrm{CO}^{2}\right)$ e outros gases resultantes da queima de combustíveis fósseis, que lançam na atmosfera, aumentando o efeito estufa, que são os gases soltos na atmosfera. Por sua vez, os céticos consideram que só parte do aquecimento global poder ser atribuída à ação humana. A quantidade de $\mathrm{CO}^{2}$ enviada à atmosfera pelas florestas em decomposição e pelos oceanos também contribui. A terra passou por outros períodos de aquecimento antes da era industrial, e não se conhecem com certeza os agentes que o provocaram.

$2^{\text {a }}$ O IPCC afirma que o primeiro passo é reduzir as emissões de $\mathrm{CO}^{2}$ para a atmosfera. A seguir é preciso aumentar a eficiência no uso de energia para queimar menos combustíveis fósseis. No entanto, os céticos argumentam que não há como frear o processo de aquecimento global nas próximas décadas. A melhor solução é investir em pesquisas para baratear energias alternativas e no futuro tornar a humanidade menos dependente de petróleo. 


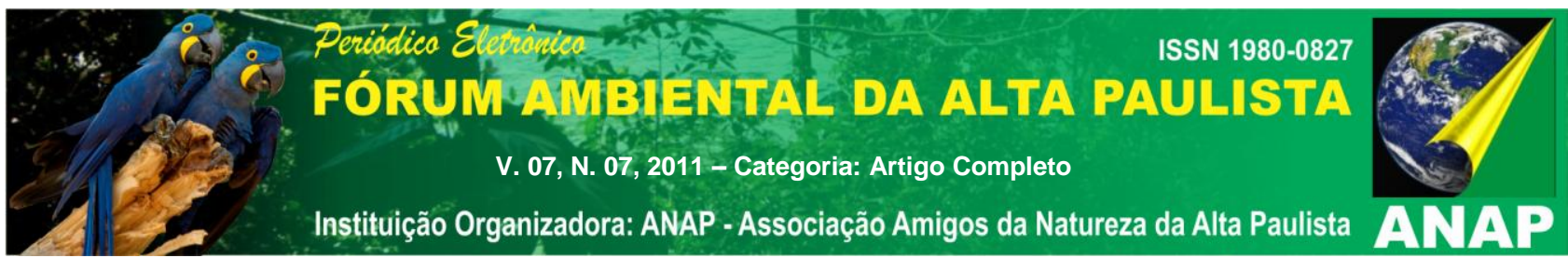

3 a Dentro de quanto tempo os efeitos do aquecimento começarão a ser sentidos? O IPCC diz que os primeiros sinais já estão presentes no aumento das enchentes; secas prolongadas e maior freqüência de grandes furacões.Os céticos estimam que os primeiros efeitos só serão perceptíveis dentro de 50 a 100 anos.

4를 Quais as severidades desses efeitos? O IPCC acha que as catástrofes naturais serão freqüentes e devastadoras. Para os céticos os desastres serão poucos. Não será difícil para o homem se adaptar a essas alterações do clima.

\section{Edição 2007/39: O combustível de Lula}

Segundo a revista veja, na ONU, Lula chama a atenção do mundo ao defender o álcool como alternativo ao petróleo. Destacando que o etanol pode reduzir a pobreza em 100 países, isto quando o então presidente participou de um discurso inaugural da reunião anual da Assembléia Geral da Organização das Nações Unidas (ONU), e aproveitou a ocasião para falar de um tema no qual o Brasil é uma autoridade em biocombustíveis, em especial o etanol produzido a partir da cana-de-açúcar.

Nesta reportagem entre outras colocações consta que nos últimos trinta anos, o país desenvolveu uma tecnologia confiável para substituir o uso de derivados de petróleo em veículos, destacando-se que a busca por combustíveis limpos e de fonte renovável é crucial no mundo de hoje, onde o Brasil tem tecnologia e recursos suficientes para liderar nessa área, conforme dito por Eduardo Viola, especialista em relações internacionais.

Apoiado em dados Lula teria mostrado que pode aumentar a produção de álcool sem necessidades de utilizar áreas hoje cobertas por florestas. O País tem terras sem aproveitamentos, de sobra, e as usinas de álcool vêm aumentando em muito a sua produtividade. 


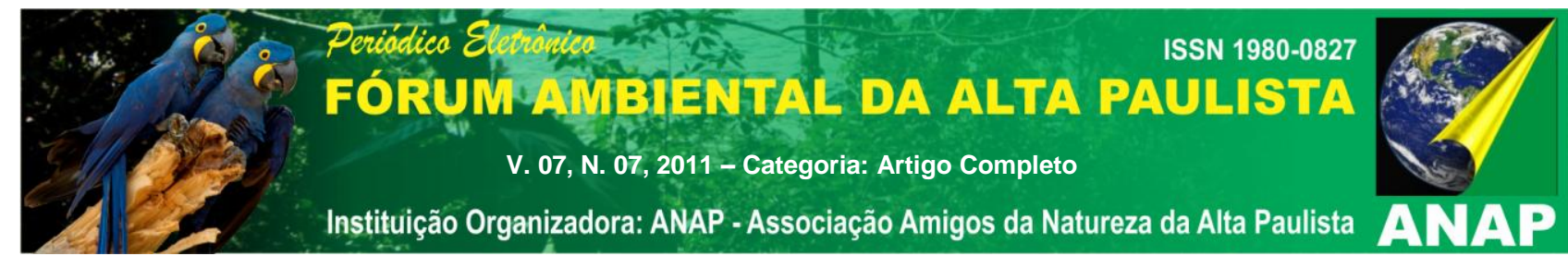

\section{Caminhos da Ciência investigativa na definição de diagnósticos em sustentabilidade}

\section{A'b Saber 2003}

Segundo Ab'Saber (2003), todos os povos são herdeiros das paisagens e todos são responsáveis pela preservação dela, desde o mais alto escalão do governo até o mais simples cidadão. Este autor revela que o espaço natural está em extinção, ficando apenas algumas áreas preservadas não úteis para o homem. Preservação? Essa palavra não existe na Natureza do Brasil, apenas se preserva com intenções capitalistas, pois há uma pressão muito grande na mídia quanto à preservação ambiental. Atualmente existe certificação para a propriedade rural que produzir ecologicamente correto, sem agredir o meio ambiente.

Em Ab'Saber (2003) encontrou-se um conceito para a palavra relictos que é utilizada para designar qualquer espécie vegetal encontrada em uma localidade específica e circundada por vários trechos de outro ecossistema. Ao mesmo tempo este autor conceitua enclave como sendo a vegetação capaz de migrar de uma região para outra totalmente diferente, sem prejudicar sua adaptação no novo ambiente, ou seja, se adapta em qualquer lugar. Vale aqui citar o caso de variedades de cactáceas.

\section{Christofoletti, 1998}

As mudanças ambientais ocorrem desde a origem da Terra, sendo o homem o grande transformador da superfície terrestre, provocando riscos tais como: ambientes terrestres, ambientes dos homens, ambientes dos animais, ambientes urbanos, ambientes 


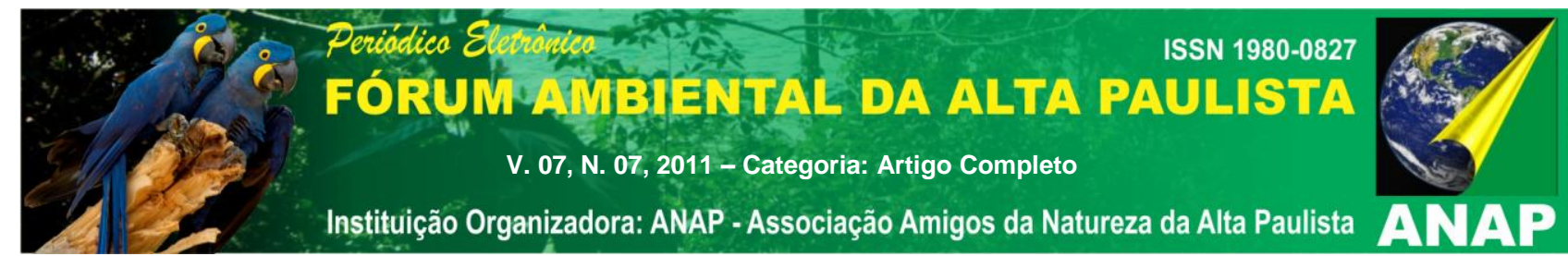

rurais. Pesquisas recentes sobre as observações e a modelagem climática têm mostrado que a ausência e a presença da vegetação podem influenciar o clima regional. Um exemplo que o autor destaca é a vegetação da Amazônia que tem um importante papel no atual clima da região e a floresta amazônica também tem um grande papel no processo hidrológico das precipitações (CHRISTOFOLETTI, 1998).

\section{Drew, 1989}

Para Drew, em termos de cultura e ambiente, o desenvolvimento da tecnologia moderna tanto industrial quanto agrícolas tem interferência das civilizações ocidentais contribuindo para as diversas transformações do meio físico.

A cultura ela é responsável pelo comportamento do homem com a Natureza, sendo necessário um trabalho com os povos conscientizando sobre a forma correta de sua preservação e valorização. Ao tratar de questões relacionadas ao controle humano sobre a Natureza, este autor utiliza de argumentação científica apoiada em Teorias Determinista, e Possibilista, principalmente.

Drew (1989) destaca que o Determinismo é a Teoria segundo a qual as condições naturais governam o comportamento do homem e até mesmo aspectos do seu caráter. Já, no Possibilismo o homem não é passível, mas sim um agente biogeográfico apto a agir sobre o meio e a modificá-lo dentro de limites naturais de espaço e de possibilidades de desenvolvimento. É um ser transformador ativo, interferindo sempre com a tecnologia sobre o espaço natural.

A Natureza nos mostra que ela tem o controle total e, mesmo com a intervenção humana ela é capaz de agir quando quer e como quer, mostrando que quem tem o poder é ela e não o homem. A Natureza vem dando varias respostas ao longo dos anos como os tsunamis, deslizamentos de terras, os furações, tornados, as inundações e o aumento da estiagem em determinadas regiões, entre outras. 


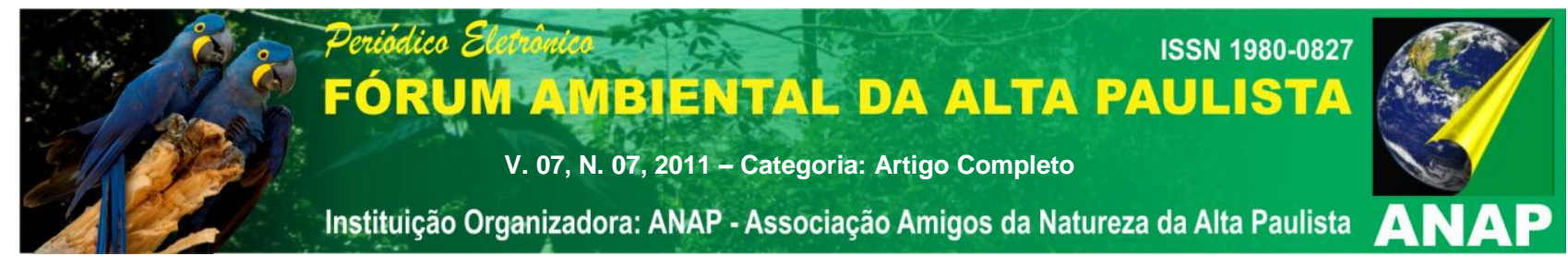

Por outro lado, de forma resumida, o conteúdo dos artigos já mencionados e daqueles selecionados chamam a atenção pela forma ao mesmo tempo em que denuncia, cria expectativas para a especulação de novos espaços aos investimentos principalmente do capital estrangeiro.

\section{CONCLUSÃO}

Da nossa busca nas publicações de Ab'Saber (2003), Cristofolleti (1998) e Drew (1989) fica claro que todos esses autores defendem a política da sustentabilidade ambiental e que isto implica em preservar para usufruir de forma continua. Ainda, para esses autores qualquer possibilidade ou tentativas de preservação dos atuais espaços do Brasil dependem das ações e reações do capitalismo.

Considerando-se a expressão: "tornar mais vantajoso manter uma arvore em pé do que cortá-la", percebe-se que a conotação cientifica que deveria ser dada a um diagnóstico com um titulo desta natureza parece realçar um tipo de solução capitalista sem incentivo a qualquer tipo de investigação cujo resultado demonstre o apontamento de uma solução para a problemática mencionada já que aqui se conclui apenas que as possibilidades encontram apenas respaldo financeiro e não da conscientização ambiental.

Soma-se a isto o artigo "o Combustível de Lula" quando se revela que a busca por tecnologia deveria ser uma forma de reduzir novos impactos ao Meio Ambiente, notadamente naquilo que mais interessa ao capitalismo, produzir mais e mais, cada vez mais com menos custo. Este artigo nos pareceu complementar o anterior porque revela uma marca oficial do governo de defender os dois lados: a Natureza e os que investem contra ela, denunciando poucas informações que possam revelar credibilidade científica.

Em Christofoletti (1998) encontramos uma espécie de alerta onde o homem é quem verdadeiramente provoca as transformações da superfície terrestre. Este mesmo autor considera que a presença e a ausência da vegetação podem influenciar o clima 


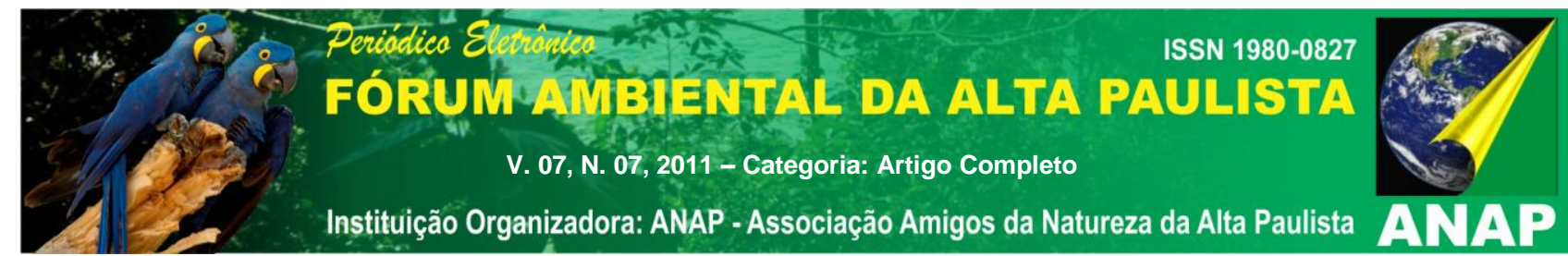

regional. Deixa claro a relação de sobrevivência interdependente entre clima, vegetação natural, precipitação e disponibilidade de água..

Adentrando as considerações de Christofoletti (1998) os autores do artigo "Os dilemas da Amazônia...", bem como do artigo "A Floresta vira Soja"(do especial Amazônia) parecem ter seguido os caminhos da investigação cientifica para a produção dos referidos artigos. Eles mostram a busca pelos antecedentes daquele ambiente divulgados pela própria revista como na inclusão de novos reconhecimentos a campo e, com base no estudo comparativo entre a investigação realizada e os cenários em transformação encontrados conseguem produzir resultados conclusivos que provam que nos espaços desmatados os avanços da ocupação antrópica, sejam dos grandes produtores e até mesmo dos assentamentos de sem-terra podendo ser considerados como formas agressivas de transformações dos ambientes climáticos e suas possíveis conseqüências futuras naquele ambiente.

Segundo Drew (1989), no Possibilismo o homem se julga no seu direito de agir sobre o meio transformando-o conforme as possibilidades de desenvolvimento. $\mathrm{Na}$ reportagem de Ronaldo Soares "O governo desmatador", o autor publica dados relevantes para mostrar uma condição de vulnerabilidade daqueles que ocupam a terra sem dispor da infra-estrutura necessária, sequer para sua própria subsistência, levando essas pessoas a considerar o espaço que the pertence como uma mercadoria de efetiva negociação. Neste artigo o autor (em nosso entendimento) chega a uma conclusão aparentemente desprovida de um levantamento de dados que the permitisse concluir de uma forma mais coerente com os princípios ditados pelas regras de preservação ambiental. Isto nos permite dizer que nas regras do Possibilismo a Sustentabilidade, neste caso, encontra-se com certeza em segundo plano.

No entendimento das considerações de Ab 'Saber 2003, em nosso país não haveria empenhos para a preservação da Natureza e que apenas se preserva com intenções capitalistas. Nesse sentido o desmatamento de forma irregular na busca de sua substituição pelas diferentes formas de ocupação da terra principalmente o que acontece 


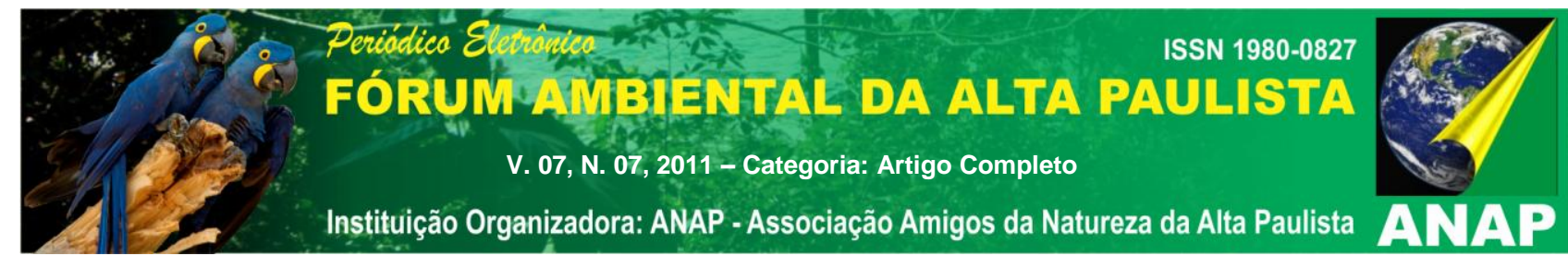

hoje, voltadas para o agronegócio e que este dos sinais visíveis de presença eterna na região nos leva a refletir a respeito dos conceitos dados por este autor às expressões relictos, e enclaves. A continuidade da não preservação pode indicar desaparecimento definitivo de espécies vegetais ao mesmo tempo em que deste desaparecimento nada sobraria que pudesse se constituir como testemunho de um processo migratório.

Em uma das publicações da revista Veja o artigo "A floresta vira soja" o autor acrescenta um subtítulo, que parece mais amenizar a intensidade do desmate com a valorização do agronegócio. Ao longo do texto é mostrada mais uma preocupação com a intensidade das ações de desmatamento na porção Mato-Grossense da Amazônia, revelando-se um ligeiro interesse dos produtores rurais em tentar salvar espaços que no futuro possam vir a ser considerada área de proteção ambiental. No entanto, somando-se o conjunto dos itens que completam o 'especial Amazônia" onde tal artigo está inserido, muda-se a ótica do entendimento que permite enxergar uma preocupação de base científica na divulgação do conjunto.

Confrontamos o que entendemos em Ab'Saber 2003 com o artigo recém comentado, onde se pressupôs que os encaminhamentos para o diagnostico da recuperação de áreas na expectativa de que um dia se torne área de preservação, não sobreviveriam os cenários de transformação que vem acontecendo atualmente naquela região. No entanto, é muito cedo para desacreditar daquilo que seria muito mais seguro cientificamente, uma vez que o artigo, isoladamente, parece que apenas reuniu informações na tentativa de considerá-la como um alerta, porém sem a devida conotação cientifica.

As obras, fontes para o entendimento do conhecimento cientifico, em Geografia nos revelou em cada uma delas que o conhecimento é fundamental para o entendimento dos problemas que afetam a superfície terrestre. Seriamos céticos se concordamos com Drew (1989) de que o determinismo ainda impõe regras ao homem para a ocupação de seus espaços? Todos os acontecimentos até aqui relatados nos faz pensar que bom seria se fomos céticos? 


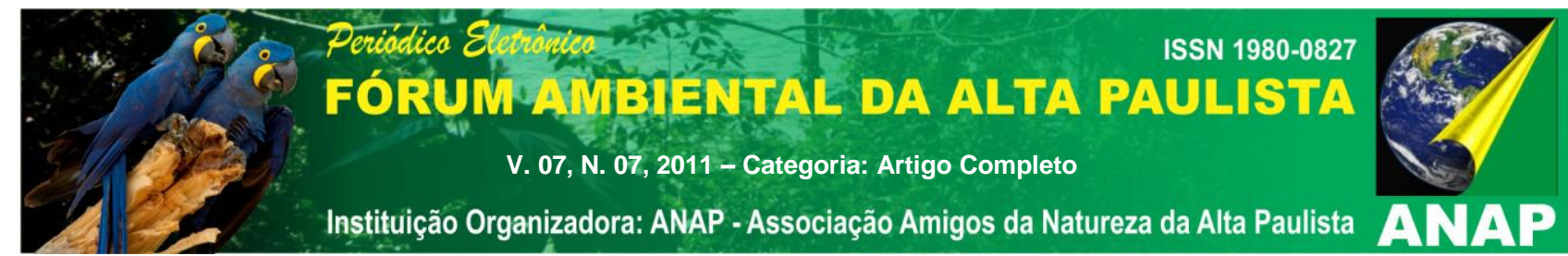

Se as mudanças ambientais como disse Christofoletti (1998), ocorrem desde a origem da terra, é porque a ciência nos dá provas disto. Na obra de autoria de A'b Saber em 2003, quando este enfatiza que a palavra preservação não existe na Natureza do Brasil, parece ceticismo?

Revendo nosso entendimento do artigo "SOS Terra países e pessoas agem... mas alguns ainda duvidam", retomamos modelos que indicam formas de conhecimento referenciadas por diferentes tipos de argumentações. De um lado o IPCC, revela que o conhecimento científico ganha, ao longo de pesquisas, resultados e outras formas de produzir verdades, que o alerta é real e que não podemos adiar a busca por soluções continuadamente. De outro aqueles que duvidam podem ser chamados de céticos, mas não necessariamente ignoram que o conhecimento é o alicerce para o entendimento da evolução do problema uma vez que ambos são cientistas e que cada grupo tem sua maneira de ver e entender o caminhar dos problemas ambientais.

Ao concordamos com a relevância cientifica desse artigo estamos tentando mostrar que a literatura geográfica consultada reforça as formas de pensamento desses dois diferentes grupos de cientistas, pois a diferença entre eles é apenas uma questão de tempo: Uns acreditam no agora, e outros no futuro, mas o fazem utilizando ciência. Então, neste artigo, revela-se a responsabilidade em informar com "jeito"de ciência.

Por fim, alerta-se para a expectativa de que, apesar da forma segura com que a notícia é veiculada, percebe-se que os assuntos, a cada "parágrafo" são conclusivos, como se fossem noticiários da mídia em jornais televisivos, carecendo de maiores investimentos no campo da investigação com o objetivo de atender/esclarecer melhor seus, com certeza, inúmeros leitores.

\section{REFERÊNCIAS}

AB'SABER, A. N. Os Domínios da Natureza no Brasil: Potencialidades Paisagísticas. Ateliê Editorial, São Paulo, 2003. 


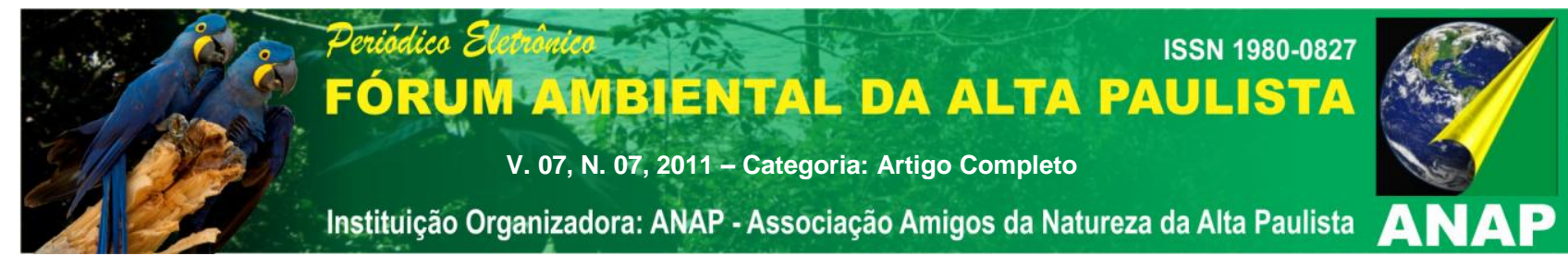

Edição Especial. Os dilemas da Amazônia. Revista Veja edição 2070 - ano 41 - n. 29 de 23 de julho de 2008. Paginas 118/121. EDITORA ABRIL. São Paulo.

CHRISTOFOLETTI, A. Geografia e Meio Ambiente no Brasil. $2^{\mathrm{a}}$ ed. Hucitec, São Paulo, 1998.

COUTINHO, L. Assim não dá. Revista Veja edição 2014 - ano 40 - n. 25 de 27 de junho de 2007. Página 67. EDITORA ABRIL. São Paulo.

DREW, D. Processos Interativos Homem-Meio Ambiente. $2^{\mathrm{a}}$ ed. Editora Bertrand Brasil. Rio de Janeiro, 1989.

EDUARD, J. Edição Especial: A floresta vira soja. Revista Veja edição 2053 - ano 41 - n. 12 de 26 de março de 2008. Páginas 114/115. EDITORA ABRIL. São Paulo.

JOLY, H. \& COUTINHO, L. O combustível de Lula. Revista Veja edição 2028 - n. 39 de 3 de outubro de 2007. Páginas 60/61. EDITORA ABRIL. São Paulo.

LIMA, R. de A. Muita retórica, pouca ação. Revista Veja edição 2064 - ano 41 - n. 23 de 11 de junho de 2008. Página 81. EDITORA ABRIL. São Paulo.

Edição Especial. Um dia muito especial. Revista Veja edição 2077 - ano 41 - n. 36 de 10 de setembro de 2008. Páginas 110/122. EDITORA ABRIL. São Paulo.

SOARES, R. O governo desmatador. Revista Veja edição 2081 - ano 41 - n. 40 de 8 de outubro de 2008. Pagina 136. EDITORA ABRIL. São Paulo.

SOUZA, O. \& Vieira. V. SOS Terra Países e pessoas agem... mas alguns ainda duvidam. Revista Veja edição 2031 - ano 40 - n. 42 de 24 de outubro de 2007. Páginas 86/96. EDITORA ABRIL. São Paulo. 